\title{
Orígenes y transformaciones del aprendizaje en línea (E-learning). Innovaciones educativas mediadas por paradigmas tecnológicos ${ }^{1}$
}

\author{
Luis Rubén Pérez Pinzón ${ }^{2}$ \\ Universidad Autónoma de Bucaramanga, Colombia
}

Recepción: 16/04/2020

Evaluación: 23/04/2020

Aprobación: 04/05/2020

Artículo de Investigación-Científica

DOI: https://doi.org/10.22267/rhec.202424.74

\section{Resumen}

La pandemia asociada con el COVID19 ha consolidado el uso del aprendizaje en línea (E-learning) como la modalidad educativa que todas las instituciones educativas de Colombia deben adecuar para dar continuidad a los procesos formativos a través de aulas virtuales, que aseguran el aislamiento y confinamiento de los estudiantes como población vulnerable. El objetivo de este artículo es describir los procesos históricos de consolidación del conectivismo instruccional como alternativa educativa mediada y subordinada a los cambios en los paradigmas y dispositivos tecnológicos. Resultado de un proyecto de investigación sobre el E-learning en Colombia, desde un enfoque cualitativo, se realiza un análisis comparativo de fuentes sobre la Historia de la educación mediada por la informática, se presenta un relato cronológico de las transformaciones del aprendizaje mediado por los dispositivos electrónicos, así como los retos conectivistas que tiene el E-learning se sistematizan para su reafirmación como innovación educativa en tiempos de crisis y no solo un medio tecnológico para dar continuidad a las prácticas y tradiciones de aprendizaje presencial.

1 Este artículo se deriva de la investigación: "Perspectivas investigativas en "innovación educativa" de la Universidad Autónoma de Bucaramanga desde el enfoque de la Educación en Línea (E-learning)" avalada por la Universidad Autónoma de Bucaramanga, Colombia

2 Docente de la Universidad Autónoma de Bucaramanga, Colombia. Grupo de investigación: Transdisciplinariedad, cultura y política. Línea de investigación: Representaciones, Memoria e Institucionabilidad(MRI).Correo electrónico: Lperez14@ unab.edu.co. 난 htps://orcid.org/0000-0003-0387-6035 
Las conclusiones reiteran la importancia de los paradigmas tecnológicos y la accesibilidad a dispositivos personalizados e interconectados para garantizar los procesos de aprendizaje en línea, la accesibilidad asincrónica de las personas o grupos aislados y el diseño instruccional a través de plataformas que propician el aprendizaje colaborativo.

Palabras clave: aprendizaje en línea; aprendizaje virtual; E-learning; paradigma; tecnología.

\title{
Origins and transformations of online learning (E-learning). Educational innovations mediated by technological paradigms
}

\begin{abstract}
The pandemic associated with COVID-19 has consolidated the use of online learning (E-learning) as the educational means that all educational institutions in Colombia must adapt in order to continue with the teaching and learning processes through virtual classrooms to guarantee the isolation and lockdown of students regarded as vulnerable population. This article aims to describe the history of instructional connectivism as an educational alternative mediated and subordinated to changes in paradigms and technological devices. A comparative analysis of the history of computer-mediated education and a chronological account of the learning transformations mediated by electronic devices is presented in this qualitative study, as well as the challenge in terms of connectivity in E-learning intended as an educational innovation in times of crisis and not only as a technological means to continue with the face-to-face classroom practices and traditions. The conclusions of the article reaffirm the importance of technological paradigms and the access to personalized and interconnected devices to ensure online learning processes, asynchronous accessibility of individuals or isolated groups and instructional design through platforms that encourage collaborative learning.
\end{abstract}

Keywords: online learning; virtual learning; e-learning; paradigm; technology. 


\section{Origens e transformações da aprendizagem online (E-learning). Inovações educacionais mediadas por paradigmas tecnológicos}

\section{Resumo}

A pandemia associada ao COVID19 consolidou o uso da aprendizagem online (E-learning) como a modalidade educacional que todas as instituições de ensino na Colômbia devem adaptar para dar continuidade aos processos de formação através de salas de aula virtuais, que garantem o isolamento e confinamento de alunos como população vulnerável. O objetivo deste artigo é descrever os processos históricos de consolidação do conectivismo instrucional como alternativa educacional mediada e subordinada a mudanças de paradigmas e dispositivos tecnológicos. Resultado de um projeto de pesquisa sobre E-learning na Colômbia, a partir de uma abordagem qualitativa, é realizada uma análise comparativa de fontes sobre a História da educação mediada pela informática, se apresenta um relato cronológico das transformações da aprendizagem mediada por os dispositivos eletrônicos, assim como os desafios conectivistas que o e-learning apresenta, são sistematizados para sua reafirmação como inovação educacional em tempos de crise e não apenas um meio tecnológico para dar continuidade às práticas e tradições da aprendizagem presencial. As conclusões reiteram a importância dos paradigmas tecnológicos e da acessibilidade a dispositivos personalizados e interligados para garantir processos de aprendizagem online, acessibilidade assíncrona de indivíduos ou grupos isolados e desenho instrucional através de plataformas que promovam a aprendizagem colaborativa.

Palavras-chave: aprendizagem online; aprendizagem virtual; e-learning; paradigma; tecnología.

\section{Introducción}

La educación en Occidente ha estado en permanente transformación e innovación a partir de los cambios tecnológicos. La primera gran innovación educativa fue la transición de los libros hechos a mano en los monasterios o 
los talleres de copiado por los libros hechos de forma masiva en las imprentas del siglo XVI, a partir de lo cual se justificó la consolidación y expansión de las universidades del Renacimiento y, en especial, la expresión de diversidad de ideas, teorías e interpretaciones de la realidad para el enriquecimiento de la enseñanza y el aprendizaje a través de medios impresos. ${ }^{3}$

A esa innovación en las prácticas didácticas, las concepciones pedagógicas y las proyecciones formativas, se sumó, en el siglo XIX, el uso de los periódicos para estudiantes, docentes (instrucción educativa) y público en general (instrucción pública) como recurso de mejoramiento y transformación de las prácticas educativas a través de escenarios formativos distantes, a los cuales se aunó el uso didáctico y las particularidades pedagógicas de la innovación educativa mediada por invenciones como la radio, la televisión, el cine y la multimedia informática, al combinar las tecnologías precedentes. ${ }^{4}$

Desde las últimas tres décadas del siglo XX, a la renovación e innovación educativa las han mediado las nuevas tecnologías de la información y la comunicación (TIC), asociadas con las redes sociales y la democratización en el acceso a la información informáticas mundial (WWW), como parte de una red regulada por las instituciones militares y de inteligencia de los Estados (Web), empresas creadoras de contenidos (Web1) o al liberar la creación y promoción de contenidos a los usuarios a través de diferentes aplicaciones y herramientas en línea (Web2), como parte de la "educación móvil".

Debe insistirse en el uso del adjetivo "nuevas", porque las tecnologías electrónicas, analógicas y mecánicas precedentes cumplieron el mismo papel e impacto como novedad transformadora y símbolo de progreso entre las generaciones y proyectos educativos anteriores a la generación tecnológica de inicios del siglo XXI. Desde entonces, la premisa dominante de los gobiernos y la burocracia educativa ha sido dar mayor importancia e influencia a los recursos digitales en el sistema educativo de cada país $\mathrm{y}$, en particular, en la masificación tecnológica o la certificación de la formación profesional de la mano de obra calificada, por lo que ha resultado incuestionable desde las profesiones que: “...las universidades necesitan

3 Luis Pérez, Revoluciones tecnoeducativas de los europeos civilizadores (Bucaramanga: División de Publicaciones UIS, 2014).

4 Alvin Toffler, La tercera ola (Barcelona: Plaza y Janés, 1993).

5 Manuel Castells, Redes de indignación y esperanza: los movimientos sociales en la era de Internet. (Madrid: Alianza, 2015). 
involucrarse en procesos de mejora de la calidad, y esto en nuestro terreno quiere decir procesos de innovación docente apoyada en las TIC". ${ }^{6}$

A la innovación educativa de la computadora científica (décadas de los sesenta y setenta) y el ordenador personal conectado a la Internet (década de los ochenta y noventa) para mejorar los procesos educativos y la calidad en el aprendizaje, se ha sumado el 'espejismo paradigmático' de la tecnología portátil para el fomento de la comunicación a través de diferentes dispositivos móviles e interconectados a una misma red electrónica global (siglo XXI). Ante esto, se ha asumido que solo a través de la mediación tecnológica se consolidan procesos de innovación, tanto pedagógica como institucional, al lograr la intermediación funcional de las máquinas lo que los procesos docentes estructurales no alcanzan; es decir, calidad en los procesos, elevadas prácticas, resultados estandarizados y apertura al trabajo colaborativo en red acorde al modelo y paradigma conectivista. ${ }^{7}$

Como resultado del proyecto de investigación titulado "Perspectivas investigativas en "innovación educativa" de la Universidad Autónoma de Bucaramanga, desde el enfoque de la Educación en Línea (E-learning)" (UNAB, Acta 28-2019), mediante el cual se logró el contraste de las fuentes y análisis históricos sobre el devenir de la educación mediada por la informática, a partir de la caracterización de las propuestas en innovación educativa de los trabajos de grado de la Maestría en E-learning de la Universidad Autónoma de Bucaramanga (UNAB) y la Universitat Oberta de Catalunya (UOC), esta reflexión indaga por cuáles han sido los orígenes y generaciones de cambio del E-learning como modalidad y recurso de aprendizaje antes de su declaratoria como estrategia permitida y promovida por el Estado colombiano desde marzo de 2019, fecha desde la cual se dispuso la continuidad de los procesos educativos a través de la mediación tecnológica ante el temor de contagio y expansión del COVID19 entre las comunidades educativas globales. ${ }^{8}$

6 Jesús Salinas, Innovación educativa y uso de las TIC (Sevilla: Universidad internacional de Andalucía, 2008), 16.

7 George Siemens, "Connectivism: A Learning Theory for the Digital Age", International Journal of Instructional Technology and Distance Learning, http://www.itdl.org/Journal/Jan_05/article01.htm, (agosto 2019).

8 Ministerio de Educación Nacional (MEN). Directiva Ministerial No. 04: Uso de tecnologías en el desarrollo de programas académicos presenciales (Bogotá: MEN, 22 de marzo de 2020), https://www.mineducacion.gov.co/1759/articles-394296_recurso_1. pdf (abril 2020). 


\section{Metodología}

A partir de la perspectiva del enfoque cualitativo de investigación se analiza el contenido de las representaciones históricas sobre el E-learning entre publicaciones científicas europeas y americanas acerca de la temática, para contrastar de forma histórica y longitudinal sus postulados con el devenir del aprendizaje en línea en Colombia.

\section{Planteamiento del problema}

El reconocimiento de la modalidad de aprendizaje "virtual", por el Decreto 1330 de 2019, del Ministerio de Educación Nacional de Colombia, y la adopción de estrategias del E-learning para sustituir de forma coyuntural la educación presencial, ante el aislamiento preventivo de la pandemia de 2020, conlleva realizar una reflexión histórica mediante la cual se analice: ¿cuáles han sido los orígenes y transformaciones del aprendizaje en línea (E-learning)?, ¿cuáles han sido sus innovaciones y paradigmas tecnológicos?

\section{Fundamentos de la innovación educativa en línea}

La innovación educativa en el siglo XXI se ha regulado por concepciones tecnológicas y tecno-democráticas asociadas con principios como la flexibilidad, accesibilidad, bajo costo y experiencias significativas a lo largo de la vida. Y, consigo, las instituciones educativas, presionadas por la dinámica del mercado de consumo que exige fuesen "innovadoras", optaran por abandonar prácticas y objetos tecnológicos tradicionales, así como sus saberes didácticos precedentes, para "promover experiencias innovadoras en el campo de los procesos de enseñanza-aprendizaje apoyados en las TIC". ${ }^{9}$

Cada transformación educativa ha exigido la renovación pedagógica mediada o condicionada por la innovación tecnológica de cada uno de los procesos educativos, así como exige una apropiación de la innovación con cambios graduales que se diseminan, hasta que se constituyen en

9 Salinas, "Innovación educativa y uso de las TIC", 17. 
sistemas totales (perspectiva funcional). ${ }^{10}$ Los cambios tecnológicos generan transformaciones en las convicciones, valores y proyecciones de cada comunidad educativa como parte de la innovación sistémica esperada o reafirmada desde las acciones planeadas y deliberadas para alcanzar los objetivos transformadores del sistema educativo (perspectiva reduccionista). ${ }^{11}$ Así mismo, esos cambios exigen modificación en los recursos materiales de aprendizaje, al concebirse que el cambio en los sistemas y los comportamientos requiere modificaciones en los medios tecnológicos que los acompañan y, por ende, la "innovación tecnológica" en la educación lleva a que los nuevos materiales se utilizaran con empleo de nuevas prácticas, concepciones e imaginarios entre los consumidores (Perspectiva estructural). De allí que toda innovación en el sector de la educación exija de las instituciones la transformación de sus proyecciones y presupuestos de gastos tanto en "modernización" como en las concepciones, recursos y prácticas como parte de un proceso complejo manifiesto con la apropiación de prácticas globales, mejoras curriculares, interdisciplinariedad en contenidos y actividades, así como la revisión y mejora de los modelos pedagógicos empleados. ${ }^{12}$

\section{Orígenes del E-learning}

El aprendizaje electrónico, abreviado con la expresión "E-learning" (electronic learning), es la forma usual de referirse al paradigma contemporáneo de aprendizaje conocido como aprendizaje en línea o educación virtual. Se explica el uso de la letra inicial "E" por el uso necesario y articulado de dispositivos electrónicos con programación informática a través de redes tecnológicas institucionales (Intranet) y redes de comunicaciones globales (Internet), mediadas integralmente con la

\footnotetext{
${ }^{10}$ Luis Pérez, "Tendencias y concepciones del E-learning en investigaciones educativas innovadoras", en: Innovación docente e investigación en educación (Madrid: DykinsonUniversidad de Murcia, 2020). 451-460.

${ }^{11}$ Ciro Dussán y Fabián Guevara, "Comparativo entre la tecnología de redes $4 G$ y $5 G$ y los beneficios de su implementación en Colombia”. (Tesis de la tecnología en Sistemas de Información, Universidad Santiago de Cali, 2019).

${ }^{12}$ Gráinne Conole, Review of pedagogical models and their use in e-learning (2010), https:// www. slideshare.net/grainne/pedagogical-models-and-their-use-in-elearning-20100304 (marzo 2020)
} 
regulación de procesos desde plataformas de administración del aprendizaje y sus contenidos (LMS). ${ }^{13}$

A diferencia de otras modalidades de aprendizaje a distancia mediadas por tecnologías de la comunicación (prensa, cine, radio, televisión, teleconferencia, etc.), ${ }^{14}$ el E-learning centra el diseño curricular de contenidos y uso didáctico de recursos informáticos en la experiencia autónoma de aprendizaje por parte del estudiante. Con esto, el papel del docente se limita a asesorías o tutorías ante las inquietudes de los estudiantes y la evaluación de sus productos, acorde a rúbricas pre-establecidas. Esa combinación funcional de recursos que conecta dispositivos, informática, tecnología y comunicación han hecho del E-learning la mejor expresión de las formas contemporáneas de la globalización tecnológica y la sociedad del conocimiento asociadas con la cuarta revolución industrial, también asumida como de la automatización ciber-física o del darwinismo tecnológico. Ejemplo de ello son los "asistentes virtuales" de los usuarios que evidencian los avances en inteligencia artificial incorporados a los servidores corporativos y la telefonía móvil (Siri de Apple, Asistant de Google, Alexa de Amazon, Cortana de Microsoft, etc.). ${ }^{15}$

Para reafirmar la relación del E-learning con plataformas informáticas con fines educativos, los investigadores educativos han optado por incorporar en sus análisis condiciones propias de los paradigmas psicopedagógicos dominantes a los resultados esperados, entre los cuales están el aprendizaje activo, flexible, colaborativo y por competencias. Con esto, el E-learning se ha redefinido, como parte de su "segunda generación" de desarrollo, como el aprendizaje promovido desde una plataforma de capacitación no presencial que:

a través de plataformas tecnológicas, posibilita y flexibiliza el acceso y el tiempo en el proceso de enseñanza-aprendizaje, con adecuación a las habilidades,

${ }^{13}$ Francisco García "Estado actual de los sistemas e-learning", Revista Teoría de la Educación. Vol. 2, No. 6 (2005), https://campus.usal.es/ teoriaeducacion/rev_ numero_06_2/n6_02_art_garcia_penalvo.htm

${ }^{14}$ Luis Pérez, Historia del Empresarismo en el nororiente de Colombia. Tomo 3. Empresas educativas e innovaciones didácticas en Santander (Bucaramanga: UNAB-Luis Pérez, 2015).

${ }^{15}$ Juan Cerro, Enseñar y aprender en línea. Tendencias y aplicaciones de las TIC dentro del ámbito educativo (Barcelona: Universitat Oberta de Catalunya, 2015). 
necesidades y disponibilidades de cada discente, además de garantizar ambientes de aprendizaje colaborativos mediante el uso de herramientas de comunicación síncrona y asíncrona, que potencian, en suma, el proceso de gestión basado en competencias. ${ }^{16}$

En sus inicios, el E-learning tuvo diversas definiciones y propósitos, acorde a sus usuarios. Para los pedagogos, era un recurso educativo para generar nuevos contextos y entornos de aprendizaje a partir de los repositorios y redes de contenidos. Para los tecnólogos, era el medio a través del cual se podían incorporar innovaciones en software a procesos educativos a través de las plataformas de formación. Los empresarios y directivos la asumieron como la estrategia más efectiva para programar, seguir y evaluar procesos de formación del personal, acorde a objetivos y contenidos precisos. Y, consigo, los usuarios finales adoptaron al E-learning como una alternativa a los servicios de la internet y los contenidos digitales a través de soportes informáticos que facilitaban sus procesos de formación personal y permitían la realización de productos virtuales desde la ofimática. ${ }^{17}$

Dos décadas después del fomento de los procesos de aprendizaje, capacitación o formación desde la Internet, con contenidos disponibles para el mejoramiento de la red informática global, el aprendizaje en línea se ha consolidado como la interacción que solo ocurre a través de dispositivos interconectados, con uso de herramientas y dispositivos electrónicos compatibles y accesibles desde la misma red. Para este fin, las plataformas de aprendizaje han preservado las características primigenias del teleaprendizaje al incentivar la distancia física entre el docente, el estudiante y los demás usuarios, lo cual reduce costos logísticos, precios de matrícula y procesos administrativos. ${ }^{18}$ También se incrementó la flexibilidad en los tiempos, accesos (sincrónico o asincrónico) y espacios de estudio al primar la comodidad y ritmo de aprendizaje de cada estudiante, lo que tornó exponencial la comunicación multimedial, interactiva, inmediata y constante entre los participantes de cada curso de formación. Los administradores y docentes-tutores asumieron, a su vez, el compromiso

\footnotetext{
$\overline{{ }^{16} \text { García, "Estado actual de los sistemas e-learning", } 2 .}$

${ }^{17}$ Jordi Planella et al., Desarrollo organizativo del e-learning. Aspectos sociales y culturales del e-learning (Barcelona: UOC, 2003), 21.

${ }^{18}$ José Cifuentes et al., "El rol del profesor en la modalidad a distancia". Revista Boletín Redipe (Red Iberoamericana de Pedagogía). Vol. 9. No. 1 (2020): 79-90.
} 
de actualización periódica del diseño, la seguridad, los contenidos de aprendizajes y la conectividad entre esos nuevos "modelos eficientes". ${ }^{19}$

Estos cambios han conllevado la transformación de las prácticas dominantes de la educación presencial al promoverse de forma masiva y propiciarse un sistema educativo con más estudiantes y mejores contenidos en menos tiempo y con mínimos costos que, además de propiciar la inclusión, fomenta el autoaprendizaje, el trabajo grupal colaborativo, los recursos educativos digitales (vídeos, infografías, ebooks) y la certificación virtual o por demanda de los aprendizajes adquiridos por parte del aprendiz, al asumir la condición de usuario satisfecho con el servicio y la experiencia de aprendizaje recibida. Se entiende por autoaprendizaje, desde la perspectiva de los críticos del E-learning, la: “... revitalización de didácticas y pedagogías tecnicistas y el consumo de tecnologías que permanentemente cambian, de modo que los alumnos consumidores desarrollan nuevas necesidades y mayores competencias. El individuo del autoaprendizaje ya no se deja alumnizar ni someter a lo que algunos han denominado "pedagogías del aburrido". ${ }^{20}$

\section{Características del E-learning}

La educación en línea, a diferencia de otras formas de aprendizaje en entornos no presenciales, se caracteriza de manera particular y diferenciadora porque solo es posible la promoción si se cuenta con una red de computadoras y dispositivos electrónicos, articulados a una red de telecomunicaciones constante y global que garantiza la separación física, la emancipación cognitiva y la solución colaborativa de problemas por parte del estudiante y sus intereses de aprendizaje, aíslan a docentes o tutores de esos procesos al adoptar el rol de acompañantes, concentran la planificación curricular a través de plataformas y dispositivos remotos que administran el aprendizaje (LMS), para que se impactaran por esa modalidad todos los campos, incluida la enseñanza de la Historia. ${ }^{21}$

\footnotetext{
${ }^{19}$ Alberto Martínez, "Formación y experiencia en la universidad", Revista colombiana de Educación. No. 70 (2016): 305-317.

${ }^{20}$ Martínez, "Formación y experiencia en la universidad", 310.

${ }^{21}$ Hansiswany Kamarga. "Constructing online based history learning: comparison of learning content management system (LCMS) to learning management system (LMS), Historia. Vol.12, No. 2 (2011): 225-273.
} 
El aprendizaje mediado por dispositivos electrónicos, a diferencia de otras formas de comunicación en línea, como las clases radiales, las tutorías telefónicas, los pregrabados televisivos o las clases por teleconferencia, se asocia directamente a la articulación del programa informático Internet y el sistema operativo Microsoft a los ordenadores personales con interfaces gráficas que se difundieron por todo el mundo desde 1993. La difusión, impactos y penetración en todos los ámbitos de la informática en la educación se asumieron como indicadores del desarrollo nacional y el crecimiento de la red global de telecomunicaciones. Se exige así una dinámica cambiante para la educación en línea, al llevar cada desarrollo en la Internet y la informática a sustituir las salas de cómputo y redes de acceso a través de cables a finales del siglo XX, por dispositivos portátiles en las aulas de clase y, en la última década, el uso personalizado de dispositivos móviles, con tecnologías híbridas e interconectados a redes inalámbricas de alta velocidad, que han permitido concentrar todas las tecnologías en un solo dispositivo "inteligente". ${ }^{22}$

En la medida en que los consumidores de información y conocimiento reclaman mayor acceso, más velocidad, aplicaciones acordes a sus necesidades de interacción y mejores dispositivos de edición audiovisual, la industria de dispositivos informáticos ha revolucionado la tecnología de las comunicaciones. También, han surgido corporaciones globales como Google.com, interesadas en recolectar, administrar y promover la producción de información y conocimiento de interés global (relación multidireccional) a través de aplicaciones informáticas gratuitas. Así, al priorizarse las necesidades e intereses de los consumidores por aprender, compartir y socializar conocimientos de interés común, se han desconocido o cuestionado las regulaciones comunicativas tradicionales de las instituciones estatales (aparatos ideológicos) y las dinámicas editoriales de los medios de comunicación masiva (aparatos represivos) que, a través de monopolios estatales o corporativos, manipularon la revolución tecnológica de los artefactos electromagnéticos (relación unidireccional) durante los siglos XIX y XX. ${ }^{23}$

${ }^{22}$ Lewis McAnally-Salas, "La educación en línea, su complejidad y las instituciones de educación”, en: Memorias Virtual Educa Brasil 2007 (São José dos Campos: Virtual Educa, 2007).

${ }^{23}$ Fabio Tarasow et al., "La educación en línea a través de diversos dispositivos tecnopedagógicos", en: Memorias del TIES 2012 III Congreso Europeo de Tecnologías de la Información en la Educación y en la Sociedad: Una visión crítica (Barcelona: Esbrina, 2012). 
Así mismo, las corporaciones informáticas han limitado la existencia y consolidación de los usos educativos de las tecnologías en línea al limitar y regular su uso a través de los sistemas administrativos del aprendizaje (LMS) o plataformas de soporte educativo (matrícula, configuración, actividades, evaluaciones, etc.) que diseñan y ofertan a directivos, docentes y padres para controlar el acceso a la web, así como para planificar y proyectar los procesos de aprendizaje sin considerar los intereses, necesidades $o$ expectativas específicas de los estudiantes, para primar así las visiones de los “docentes expertos" y los diseñadores instruccionales que los conciben y validan, acorde a las tendencias globales o con acatamiento de los modelos y estrategias pedagógicas institucionales. ${ }^{24}$

El aprendizaje en línea, al depender de acciones dirigidas para generar y compartir la información y el conocimiento digital bajo protocolos y estructuras informáticas seguras, ha requerido inevitablemente la adopción y adaptación institucional de plataformas de uso administrativo que centralizan las herramientas y contenidos posibles para los diferentes procesos educativos, así como complementan o mejoran los diseños instruccionales planificados por administrativos y docentes. Entre las plataformas educativas más conocidas y contratadas en América Latina, están: Bscw (comercializada desde 1995), WebCT (1997) fusionada con Blackboard (1998), Claroline (2000), Moodle (2001), Canvas (2008), etc., así como plataformas abiertas, pero con regulación corporativa, como Classroom de Google o Teams de Microsoft, para constituirse en sistemas que regulan el aprendizaje estudiantil, así como contribuyen a la capacitación y seguimiento del trabajo colaborativo de los docentes como parte de "una comunidad de práctica". ${ }^{25}$

Desde sus inicios, cada plataforma se ha concebido como un programa genérico interconectado a un servidor en la Internet desde el cual se proveen, administran, actualizan y controlan los módulos administrativos que forman parte de la configuración de un curso específico de formación (recursos de diseño y aprendizaje, matrícula de usuarios, registro de profesores,

${ }^{24}$ Yisell Góngora y Olga Martínez, "Del diseño instruccional al diseño de aprendizaje con aplicación de las tecnologías", Teoría de la Educación. Educación y Cultura en la Sociedad de la Información. Vol. 13. No. 3 (2012): 342-360.

${ }^{25}$ Natalia Fernández, Las prácticas docentes en propuestas de educación en línea. Comunidad de Práctica para la formación e investigación de prácticas de tutoría - de profesionales con y sin formación de base pedagógica - en propuestas de enseñanza en linea (Buenos Aires: PENT, 2013). 
calificaciones, organización de grupos, informes de rendimiento, etc.). Así mismo, deben servir para facilitar: “... el aprendizaje distribuido y colaborativo a partir de actividades y contenidos prediseñados, de forma síncrona o asíncrona, utilizando los servicios de comunicación de Internet como el correo, los foros, las videoconferencias o el chat". ${ }^{26}$

Al ser su objetivo simplificar los procesos de planificación educativa de los cursos e incrementar las posibilidades de actividades, recursos y contenidos para el aprendizaje, a los estudiantes se los condiciona a limitar sus procesos de aprendizaje solo a través de interconexiones desde cada plataforma, con lo cual, desde sus orígenes, los sistemas de administración del aprendizaje (LMS) se reconocieron por contar con una estructura didáctica común, según la cual: "El alumno interactúa con la plataforma a través de una interfaz web que le permite seguir las lecciones del curso, realizar las actividades programadas, comunicarse con el profesor y con otros alumnos, así como dar seguimiento a su propio progreso con datos estadísticos y calificaciones". ${ }^{27}$

Cada plataforma ofrece así una limitada oferta de libertad del aprendizaje en red y, a través de redes para los estudiantes al migrarse los procesos analógicos de regulación curricular y planificación didáctica de los docentes a entornos en línea, y consigo, es limitado su interés por crear espacios y entornos de sociabilidad e intercambio de información sin regulaciones ni condicionamientos institucionales. ${ }^{28}$ De este modo, mientras los estudiantes apelan a la educación en línea para trabajar a distancia, con distanciamiento de los controles subjetivos de docentes y directivos, paralelamente buscan acortar con esas mismas tecnologías las distancias para lograr mejores interacciones sociales. Esa búsqueda de conocimientos extracurriculares ha sido una de las razones que consolidaron a Facebook como la primera red social global desde 2004, así como en referente del blended learning para el aprendizaje mixto de disciplinas como la Historia. ${ }^{29}$

${ }^{26}$ García, "Estado actual de los sistemas e-learning", 3.

${ }^{27}$ García, "Estado actual de los sistemas e-learning", 3.

${ }^{28}$ Tarasow et al., "La educación en línea a través de diversos dispositivos tecnopedagógicos".

${ }^{29}$ Noe García et al., "Facebook como Entorno Virtual de Enseñanza Aprendizaje para diversificar la asignatura de historia en el contexto multigrado", en: Investigaciones sobre problemas educativos y sociedad. (México: Universidad Autónoma de Zacatecas, 2018), 671-680. 
A través del E-learning, la conflictiva relación presencial estudiantedocente ha pasado a ser solo un contacto esporádico e individualizado entre aprendiz-tutor que altera de forma constante las dimensiones esperadas para la educación en línea (social, académica, organizativa, orientadora, técnica, financiera) (Cabero, 2004) y requieren adaptarse a la creciente popularidad y flexibilidad de cada cambio tecnológico (multimedia en línea, páginas web, redes sociales). Esto se ha evidenciado en la creciente necesidad de migrar o actualizar las plataformas de aprendizaje (LMS a LCMS) como sistemas de administración de cursos (CMS), adaptables a cada situación o grupo y concebidas como plataformas en línea (e-plataforms) que articulan entre sí los dispositivos y redes sociales de los estudiantes y docentes como parte de macro-estrategias para concentrar su uso. ${ }^{30}$

Si bien no es posible condicionar o limitar los procesos de sociabilidad y aprendizaje que emplea cada uno de los usuarios al formar parte de una "comunidad de aprendizaje", las características de las plataformas tecnológicas que garantizan los procesos de aprendizaje del E-learning han conllevado establecer cuáles son las características del estudiante en línea o articulado a esta modalidad; es decir, es un usuario que debe ser reconocido y estar regulado por las plataformas o aplicaciones virtuales a las que se inscribe o matricula y es el centro de los procesos y diseños de aprendizaje. Sin embargo, no se le permite cuestionar el orden curricular impuesto por un tutor-docente al primar aún los criterios dominantes del evaluador de cada unidad o curso virtual y no el libre desarrollo y cumplimiento de las competencias, contenidos y metas evaluativas a cumplir en una rejilla preestablecida, a lo cual se suma la estricta consulta y uso del plan lecturas e informaciones consideradas como básicas para la aprobación de los cursos. $^{31}$

Sin embargo, a través de las plataformas de aprendizaje interactivas y sincronizadas con los demás recursos electrónicos que utilizan los usuarios en la Internet, los promotores del conectivismo esperan que cada estudiante propicie o justifique su hacer desde procesos individuales o colaborativos de investigación exploratoria que, al mediarlos los sistemas telemáticos existentes, conllevan posibilitar el aprendizaje en red, acciones didácticas

${ }^{30}$ Julio Cabero, "La función tutorial en la teleformación", en: Nuevas Tecnologías y Educación (Madrid: Pearson Educación, 2004), 129-144.

${ }^{31}$ María Llorente, "El tutor en E-learning: aspectos a tener en cuenta", Edutec. Revista Electrónica de Tecnología Educativa. Vol. 20 (2006): 1-16. 
modeladas por los mismos estudiantes y un cambio en el rol y protagonismo dominante del docente, cada uno de los cuales debe pasar a ser parte activa del proceso de revisión, investigación o construcción de aprendizaje y no solo un regulador curricular de contenidos o calificador de participaciones en foros y de productos como tareas. ${ }^{32}$

Desde su adopción y promoción en Colombia en 1982,33 a la educación a distancia o por teleformación se la ha llamado a formar un estudiante generador de informaciones y conocimientos, capaz de aprender "a buscar, seleccionar y analizar esa información en las distintas fuentes de consulta”, sin limitarse a ser solo un consumidor y reproductor de contenidos. De allí que los entornos virtuales de aprendizaje se concibieran como sistemas diseñados para permitir que: "los estudiantes sean productores de la información, proporcionando una experiencia más rica que el aprendizaje individual". ${ }^{34}$ De este modo, los estudiantes que producen contenidos y los publican a través de las páginas de la web institucional (web1) o las redes de la web social (web2) encuentran en el trabajo en red o con la colaboración de otros "colegas", como lectores, coautores o evaluadores, la oportunidad de propiciar aprendizaje cognitivo y social al: “... ayudarse mutuamente a resolver problemas, compartir información, construir conocimiento y crear un diálogo social. La colaboración motiva a los participantes y les aporta beneficios intelectuales". ${ }^{35}$

De allí el creciente interés de las plataformas diseñadas para el E-learning por ofrecer espacios de interacción entre los participantes por medio de herramientas de charla (chat), discusión (foro), encuentro (videoconferencia), trabajo grupal (debate) articuladas a su programación o conectadas a las herramientas y aplicaciones de plataformas en línea como Google o Facebook. Ejemplo de ello es la sustitución por algunas universidades latinoamericanas de plataformas usuales Moodle y Blackboard por el sistema Canvas, al considerarse que es la alternativa más interactiva en el mercado para los programas virtuales de formación en pregrado y postgrado, al conectar los recursos digitales del aula de clase

\footnotetext{
${ }^{32}$ María Pérez y Montse Guitert, Aprender y enseñar en línea (Barcelona: FUOC, 2011).

${ }^{33}$ OECD Development Centre Studies, E-learning in Higher Education in Latin America (París: OECD Publishing, 2015), 97.

${ }^{34}$ Pérez y Guitert, Aprender y enseñar en línea, 16.

${ }^{35}$ Linda Harasim et al., Redes de aprendizaje. Guía para la enseñanza y el aprendizaje en red (Barcelona: Gedisa, 2000).
} 
con las aplicaciones y redes más usados por los aprendices. Y, consigo, ofrecía acceso y seguimiento en doble vía al no dependerse solo del ingreso y consulta exclusiva a través de la plataforma al articularse los contenidos y mensajes a las redes sociales más populares que consultan los usuariosaprendices desde sus dispositivos. ${ }^{36}$

Ese aprendizaje en línea entre estudiantes que se organizan para trabajar y colaborar entre sí, sin restricciones espaciales o temporales, permite, además, interacciones de mejoramiento en la cantidad y calidad de las fuentes de información consideradas, su análisis y uso argumental, así como reducen los sentimientos adversos generados por la mediación comunicacional individualizada a través de los dispositivos y redes en la Internet; en particular, los índices de abandono o deserción, asociados con la soledad, aislamiento e interiorización de cada interacción enviada o recibida.

Los primeros programas de pregrado y postgrado universitarios establecidos en Colombia desde 1997, en asocio con el Instituto Tecnológico de Monterrey o la Universidad Oberta de Cataluña, ${ }^{37}$ aprovecharon esas fortalezas del E-learning para que los estudiantes en línea fuesen "protagonistas de las acciones formativas", fueran más activos y participativos, apelaran a sus iniciativas y capacidades creativas e innovadoras y encontraran en los tutores agentes generadores de proyección y aplicación de la información por medio de estrategias como los proyectos de aprendizaje basados en problemas. Con esto, los orientadores pedagógicos dejaron de ser solo los operadores de la plataforma y asumieron que los estudiantes con sus iniciativas podían llegar a ser "... socios y pares del docente en la construcción de conocimiento como una estrategia de aprendizaje". ${ }^{38}$

\section{Paradigmas reguladores del E-learning}

La educación en línea, como modalidad de aprendizaje que "responde a las demandas actuales de la sociedad", ha estado mediada por procesos y productos tecnológicos con el propósito de formar y garantizar a las nuevas

\footnotetext{
${ }^{36}$ Universidad Autónoma de Bucaramanga (UNAB). Bienvenido a Canvas. Tu experiencia online se transformará (Bucaramanga: UNAB, 2020), https://canvas.unab.edu.co/ (abril 2020).

${ }^{37}$ OECD, E-learning in Higher Education in Latin America, 98.

${ }^{38}$ Pérez y Guitert, Aprender y enseñar en línea, 19.
} 
generaciones de educandos las competencias para ingresar y desenvolverse en nuevos entornos laborales, cada vez más mediados por las tecnologías de la información y la comunicación de uso masivo e interconectividad dominante. Estas demandas, con la epidemia del Covid19, se constituyeron en estrategia provisional promovida por el Estado colombiano, al sugerirse: "... hacer uso de herramientas como e-Learning, portales de conocimiento, redes sociales y plataformas colaborativas, para adelantar los procesos de capacitación y formación que sean inaplazables". ${ }^{39}$

A diferencia de la educación presencial, que requiere espacios y recursos físicos para cumplir con sus objetivos, así como de la educación a distancia o mixta, que requiere elementos mediadores como plataformas, ordenadores y programas de administración del aprendizaje (LMS), la educación en línea solo requiere redes y dispositivos de acceso a la internet, de cualquier tipo, en cualquier lugar con accesibilidad constante. Esas redes se constituyen en el "espacio natural" para las nuevas formas de enseñanza, aprendizaje e innovación, dentro o fuera del aula, ${ }^{40}$ así como uno de los crecientes sectores industriales y comerciales, al ser Internet un "servicio público" imprescindible.

La educación y el aprendizaje en línea han replanteado los procesos educativos que reclamaban las nuevas dinámicas político-económicas asociadas con mercados globales, interacciones en línea, una sociedad del conocimiento o la información interconectada a redes y servicios, etc., con lo cual el aprendizaje en línea permite integrar los procesos, estrategias y recursos de aprendizaje que no logra la relación docente-libro-aula en la presencialidad, pero exige un profesorado capacitado y dispuesto a aprender a enseñar y a aprender a aprender con sus estudiantes, al estar e interactuar en línea, a través de diferentes canales digitales y con apelación a una relación tutor-plataforma-actividad-recurso. Y, consigo, se requiere que la educación virtual adopte la gradual "introducción de elementos de gestión del conocimiento dentro de la dirección de sistema universitario". ${ }^{41}$

La educación a distancia o teleformación se originó con la autoformación y titulación por correspondencia (primera generación, siglo

\footnotetext{
${ }^{39}$ Ministerio de Educación Nacional, "Directiva Ministerial No. 04”, V.

${ }^{40}$ Josep Duart y Francisco Lupiáñez, "E-strategias en la introducción y uso de las TIC en la universidad", RUSC Universities and Knowledge Society Journal. Vol. 2. No. 1 (2005): 5-31.

${ }^{41}$ Duart y Lupiáñez, "E-strategias en la introducción y uso de las TIC en la universidad", 23.
} 
XIX), ${ }^{42}$ mejorada con la realización de cursos por medio de grabaciones audiovisuales o transmisiones de radio y televisión (segunda generación, siglo XX). ${ }^{43}$ La teleformación con dispositivos informáticos, recursos multimedia y tecnologías en línea como tal (tercera generación, 1969) inició con redes de computadores conectadas entre sí desde una sala acondicionada para compartir procesos informáticos u ofimáticos básicos (primera generación del E-learning: I-learning / informatic-learning, décadas 1970-1990). ${ }^{44}$

Esas redes se mejoraron con la interconexión de los equipos de cómputo de un aula a través de la internet para compartir comunicaciones, archivos y proyectos de construcción colectiva (segunda generación: E-learning 1.0, década 1990-2000), lo que propició, después, la conexión de estudiantes a los procesos de aprendizaje presencial de manera virtual, de forma simultánea (webconferencia) o diferida (grabación), acorde a los atributos de una plataforma institucional de apoyo (tercera generación: b-learning o e-learning 2.0, década 2000-2010), con el surgimiento de innovaciones como los cursos masivos, abiertos e interconectados (MOOC) que promovieron los pioneros del conectivismo. ${ }^{45}$

La programación robotizada y mediada por la inteligencia artificial a través de herramientas de búsqueda (web3) y la articulación de todas las máquinas y dispositivos electrónicos con archivos y programas desde la internet (Web4 o internet de las cosas), ha conllevado el diseño instruccional de programas y cursos de formación plenamente configurados $\mathrm{y}$ administrados por aplicaciones $\mathrm{y}$, consigo, a reflexionar sobre una cuarta generación del aprendizaje en línea, de carácter abierto, ubicuo, móvil y multifuncional, que articula los dispositivos tradicionales con los recursos de internet y los medios de interacción e intercambio de información masiva (m-learning o e-learning 3.0, década 2010-hoy). ${ }^{46}$ De allí la importancia de

${ }^{42}$ Lorenzo García, "Historia de la educación a distancia", RIED: revista iberoamericana de educación a distancia. Vol. 2. No. 1 (1999):11-40.

${ }^{43}$ Luis Pérez, "Tecnología educativa radiofónica en la frontera colombo-venezolana a mediados del siglo XX", Anuario Colombiano de Historia Social y de la Cultura. Vol. 42. No. 1 (2015): 145-176.

${ }^{44}$ Planella, Desarrollo organizativo del e-learning, 23.

${ }^{45}$ Universidad de Salamanca, Los MOOC: Historia, Características, Realidades y Tendencias (Salamanca: Universidad de Salamanca, 2017), http://repositorio.grial.eu/ handle/grial/890 (marzo 2010)

${ }^{46}$ Begoña Gros, "La evolución del e-learning: del aula virtual a la red", RIED Revista Iberoamericana de Educación a Distancia. Vol. 21, No. 2 (2018): 1-15. 
diferenciar los procesos de aprendizaje en línea de sus entornos y recursos digitales, así como de los paradigmas psicológicos que originaron los modelos pedagógicos y diseños instruccionales que los fundamentan. ${ }^{47}$

A su vez, todos esos cambios se han relacionado con los paradigmas psicológicos aplicados a la enseñanza-aprendizaje mediados por las tecnologías de la información y la comunicación (TIC) y han partido de la necesidad de "renovación generacional" de los docentes que se resisten al aprendizaje mediado por los recursos electrónicos al emplear tecnologías análogas. Con cada cambio o mejora en los soportes y dispositivos electrónicos adaptados a los procesos de aprendizaje emergió y se consolidó una mirada futurista y una concepción prospectiva sobre la relación Escuela-TIC, cada una de las cuales se basa en los principales paradigmas psicológicos que fundamentan los modelos pedagógicos para el desarrollo, incorporación y penetración de la tecnología en la educación, así como en la transformación de la educación a partir de la incorporación de tecnologías globales para la satisfacción de necesidades o expectativas individuales. ${ }^{48}$

El primer paradigma promovido con la incorporación de las TIC a las aulas fue la enseñanza programada (década de los 70 , del siglo $\mathrm{XX}$ ), acorde al modelo psicológico conductista y mecanicista. Desde esa corriente psicológica, las TIC se emplearon como recursos para analizar el comportamiento observable desde los estímulos-respuestas, la programación instruccional y la medición de la conducta a través del aprendizaje asociativo. Sus principales autores fueron Wundt y Watson, ${ }^{49}$ quienes promovían un paradigma caracterizado por el aprendizaje de comportamientos y estímulos planeado por objetivos, administrado por los docentes, regulado por medio de cursos y centrado en la repetición ampliada de contenidos informáticos. ${ }^{50}$

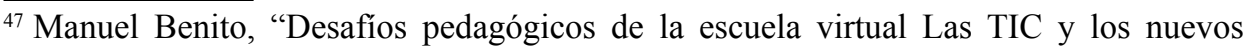
paradigmas educativos", Telos. Cuadernos de Comunicación e Innovación. No. 78 (2009): 63-75.

${ }^{48}$ Benito, "Desafíos pedagógicos de la escuela virtual Las TIC y los nuevos paradigmas educativos", 64

${ }^{49}$ Eulália Torras, Aproximación conceptual a la enseñanza y aprendizaje en línea (Barcelona: FUOC, 2015), 18-22.

${ }^{50}$ Robert Tennyson, The impact of the Cognitive Science Movement on Instructional ID Fundamentals. Instructional design fundamentals: a reconsideration (New Jersey: Educational Technology Publications, 1995). 
El segundo paradigma fue la enseñanza asistida (década de los 80), caracterizada por la transición del modelo conductista al cognitivista, en que cognitivismo se entendía como la corriente psicológica que tiene por objeto los procesos mentales (percepción y memoria) y la resolución de problemas en la construcción de conocimientos, así como la adaptación de la persona al entorno y los conflictos (crecimiento/ajuste/reestructuración) entre los conocimientos previos y la información. Sus principales autores son Rumelhart y Norman, ${ }^{51}$ quienes propendían por un paradigma caracterizado por el aprendizaje planeado desde construcciones mentales asociadas con entradas y salidas, acorde al modelo computacional, mediante las cuales se promueven aprendizajes individuales, a partir de procesos cognitivos prediseñados, de carácter memorístico. ${ }^{52}$

El tercer paradigma asociado es la enseñanza interconectada (década de los 90), con su principal característica: la plena adopción del modelo constructivista. Para ello, se asume que el docente, como orientador de cada aprendiz, contribuye a la construcción gradual, la reconstrucción radical, la regulación metacognitiva y la auto-programación entre los conocimientos previos y la información nueva desde la asimilación (o integración por equilibrio) y la acomodación (modificación por necesidad). Sus principales inspiradores fueron Piaget y Vygotsky, ${ }^{53}$ quienes sentaron las bases de un paradigma caracterizado por el aprendizaje planeado por cada estudiante para que le resultara significativo, a partir de la autoselección de soluciones a sus necesidades individuales y el diálogo colaborativo con sus pares de aprendizaje, con empleo gradual de la tecnología como mediación informativa o de interacción social. ${ }^{54}$

El cuarto de los paradigmas es la enseñanza desde el aprendizaje interactivo (flexible o E-learning) (mediados de la década de los 90), caracterizado por la transición entre el modelo constructivista y el preconectivista. El conectivismo es el aprendizaje flexible, que se concibe y propicia entre redes colaborativas y conexiones sociales seleccionadas por los mismos aprendices, con fundamento en el interaccionismo simbólico; es decir, por la corriente psicológica que tiene por objeto la facilitación social del aprendizaje desde los significados (subjetividad),

\footnotetext{
${ }^{51}$ Torras, Aproximación conceptual a la enseñanza y aprendizaje en línea, 22-27.

${ }^{52}$ Siemens, "Connectivism: A Learning Theory for the Digital Age", 5

${ }^{53}$ Torras, Aproximación conceptual a la enseñanza y aprendizaje en línea, 28-33.

${ }^{54}$ Siemens, "Connectivism: A Learning Theory for the Digital Age", 3
} 
interpretaciones (interacciones) y elaboraciones (funciones-acciones) que ocurren en las interacciones virtuales o presenciales de conocimiento. $\mathrm{Su}$ principal promotor ha sido G. Mead, ${ }^{55}$ y sus seguidores.

El quinto paradigma es el aprendizaje compartido desde el libre acceso (primeras décadas del siglo XXI), caracterizado por el modelo conectivista o post-constructivista, mediante el cual se promueve el aprendizaje por medio de recursos y ambientes cambiantes a los que pertenece el individuo, pero no tiene pleno control sobre ellos, al centrarse en la interconexión de informaciones, las conexiones sociales virtuales, la actualización constante de los conocimientos y el libre acceso o aprendizaje por los usuarios. ${ }^{56}$

El modelo asociado con el conectivismo corresponde plenamente con un diseño en línea y una relación semi-automatizada del estudiante con otros estudiantes como parte de grupos o redes antes que individualidades (web2) a través de portales, programas y redes conectadas a la internet. Así mismo, la relación de los docentes con los estudiantes se condiciona por su integración a redes sociales con contenidos y recursos especializados, reguladas por el "software social" de libre acceso y administración por el usuario registrado. De tal modo, el aprendizaje se basa en contenidos y recursos que buscan, consultan o crean directamente los estudiantes (prosumidores: de consumidores a creadores de contenido), desde los servidores virtuales y las redes sociales que consultan y alimentan otros usuarios de la Internet, por lo que es posible acceder a ese "modelo ecológico" de interconexiones con el usuario registrado o autorizado para ingresar a una plataforma. ${ }^{57}$

Así, el paradigma conectivista promueve un aprendizaje centrado y mediado "fuera de la persona", como parte de comunidades de práctica que contribuyen en red con recursos y contenidos colaborativos en permanente mejora y actualización, ${ }^{58}$ con lo que sientan las bases del aprendizaje flexible inteligente, propuesto por Taylor, o el aprendizaje ecológico virtual de Siemens, mediados por la inteligencia artificial. La penetración en el Sistema educativo es continua y constante al ampliarse y garantizarse el libre

\footnotetext{
${ }^{55}$ Torras, Aproximación conceptual a la enseñanza y aprendizaje en línea, 33-36.

${ }^{56}$ Siemens, "Connectivism: A Learning Theory for the Digital Age", 5-6.

${ }^{57}$ Conole, Review of pedagogical models and their use in e-learning, 3.

${ }^{58}$ Benito, "Desafíos pedagógicos de la escuela virtual Las TIC y los nuevos paradigmas educativos", 69.
} 
acceso a las redes sociales de interacción y sus contenidos informativos, a partir de los cuales se fortalecen las conexiones entre individuos y redes, al generarse nodos y portales que acrecientan el flujo de información, fuera de las personas y sin control de las personas. ${ }^{59}$

Esas comunidades de práctica, que promueve el conectivismo, logran integrar y fortalecer otros paradigmas psicológicos y sus modelos pedagógicos de aprendizaje, como son: el aprendizaje colaborativo en línea, que considera la multiplicidad, la activación, autenticidad, producción constante (insuficiencia nula), interdependencia y articulación de las experiencias previas para construir conocimiento; aprendizaje comunitario en línea, mediado por la presencia social y la presencia docente; aprendizaje por redes, a partir de la presencia social y las interacciones de los estudiantes en la Internet, y el autoaprendizaje en comunidades, donde cada aprendiz es una persona activa que contribuye en la construcción de conocimiento e identidad. ${ }^{60}$

A quienes promueven el aprendizaje en línea en cualquiera de las submodalidades del E-learning (blend-, electronic-, mobile-, open, ubicuos-, TV-learning) se los condiciona a fortalecer los beneficios y flexibilidades del "aprendizaje social" que se promueve con la modalidad virtual, al primar tanto el aprendizaje colaborativo como el autoaprendizaje. ${ }^{61}$ Se evidencia así que el aprendizaje en línea es el más flexible en accesos, costos y tiempos, utiliza con creatividad los contenidos virtuales, pero requiere infraestructura y dispositivos informáticos suficientes, procesos de acompañamiento colaborativo y comprometido de los docentes y mejora constante de los productos, que evidencien los aprendizajes alcanzados como parte de la transformación entre usuarios y tutores. Con esto, no puede reducirse la "virtualización" a un modelo pedagógico que resulta ser una innovación educativa que sustituye temporalmente a la educación presencial, como pretende el Gobierno colombiano mientras cesa la pandemia.

\footnotetext{
${ }^{59}$ Torras, Aproximación conceptual a la enseñanza y aprendizaje en línea, 38.

${ }^{60}$ Torras, Aproximación conceptual a la enseñanza y aprendizaje en línea, 42-65.

${ }^{61}$ Claudia Guerrero, "Diagnóstico de la deserción en dilemas sociales en el aprendizaje colaborativo en ambientes e-learning". (Trabajo de Investigación de Maestría en E-learning, Universidad Autónoma de Bucaramanga, 2011).
} 


\section{Conclusiones}

El E-learning ha sido la modalidad de aprendizaje que ha surgido y se ha transformado a la par de los cambios en la tecnología informática y la conectividad a través de la Internet. Esas transformaciones han requerido mejorar los diseños instruccionales para las plataformas y campus que median la relación entre docentes y estudiantes en las aulas virtuales, así como reconocer la existencia de herramientas intuitivas y aplicaciones adaptativas, que han motivado al estudiante a asumir el aprendizaje fuera de todo tipo de aula y a buscar otras experiencias, acordes a interés o necesidades personalizadas. Experiencias exitosas de esos cambios en el aprendizaje han sido los cursos virtuales masivos, en los cuales el autoaprendizaje y la autorregulación son los factores de éxito de los aprendices en línea, sin importar la calidad o cantidad de los contenidos en sus entornos. ${ }^{62}$

El aprendizaje en línea, durante sus primeras generaciones, requirió emplear y articular, a través de la tecnología con la que se contaba, las prácticas y didácticas heredadas de la enseñanza memorística, activista $\mathrm{o}$ conductista, que empleaba recursos impresos, radiales, fílmicos o televisivos para complementar los procesos de aprendizaje, acorde a los intereses, expectativas y concepciones del docente. Sin embargo, las tecnologías informáticas y la personalización de los dispositivos para su funcionamiento han permitido el fomento de comunidades de aprendizaje, en las cuales es posible el trabajo colaborativo para desarrollar proyectos colectivos o el autoaprendizaje, acordes a los intereses y expectativas de cada estudiante. Ejemplo de ello es el número creciente de cursos o audiovisuales que, a modo de "tutoriales", sustituyen la presencia y autoridad cognitiva del docente, lo que da paso a las vivencias y saberes de otros aprendices desde cada canal.

A pesar de la reducción del E-learning, por parte del Estado colombiano, a solo una modalidad no presencial o virtual para facilitar el acceso al conocimiento de quienes no pueden asistir a las aulas presenciales, con adecuación, para este fin, de las prácticas exitosas en educación a distancia mediada por la prensa, el cine, la radio o la televisión, así como al asumir, en tiempos de crisis y pandemia, que el aprendizaje en línea se reduce a realizar a través de la tecnología informática las mismas prácticas de

${ }^{62}$ Gros, "La evolución del e-learning: del aula virtual a la red", 2 
la educación presencial, el E-learning ha demostrado su capacidad de adecuarse a cada etapa de cambio durante la actual revolución tecnológica (o cuarta revolución). ${ }^{63}$ Esto conllevará gradualmente la transición de la tecno-dependencia, que caracteriza a las plataformas institucionales de contenidos, acordes a los paradigmas conductistas y constructivistas, para dar paso a ambientes virtuales abiertos, que priorizaran el aprendizaje social y práctico, a través de las diferentes herramientas asociadas con la internet, acordes al paradigma conectivista.

Esa creciente dependencia y variación de los aprendizajes en línea, acordes a los cambios en las tecnologías comunicativas que los soportan (computadores de escritorio, ordenadores portátiles, dispositivos inalámbricos, etc.), ha conllevado que al E-learning se le asocien características negativas o desventajas propias de la E-exclusión, resultantes de la "ingenierización" de los recursos y procesos educativos. De allí que los procesos de E-inclusión, para el fomento de la innovación desde el "social e-learning", antes que la compra y uso de más dispositivos, promuevan un aprendizaje significativo, que retornara a los orígenes mismos del aprendizaje en línea, como son: la autorregulación ante los procesos sociales de consumo y aprovisionamiento electrónico, la competitividad en redes y servicios públicos (electricidad, banda ancha, puestos de trabajo), el tecno-alfabetismo, la divergencia temática y la flexibilidad en tiempos de estudios o descanso, etc.

\section{Referencias}

Benito, Manuel. "Desafíos pedagógicos de la escuela virtual Las TIC y los nuevos paradigmas educativos". Telos. Cuadernos de Comunicación e Innovación. No. 78, (2009): 63-75.

Cabero, Julio. "La función tutorial en la teleformación". En: Nuevas Tecnologías y Educación. Madrid: Pearson Educación, 2004. 129-144.

Castells, Manuel. Redes de indignación y esperanza: los movimientos sociales en la era de Internet. Madrid: Alianza, 2015.

Cerro, Juan. Enseñar y aprender en línea. Tendencias y aplicaciones de las TIC dentro del ámbito educativo. Barcelona: Universitat Oberta de Catalunya, 2015.

${ }^{63}$ Yuval Harari, Homo Deus. (Barcelona. Debate, 2016). 
Cifuentes, José et al. "El rol del profesor en la modalidad a distancia". Revista Boletin Redipe (Red Iberoamericana de Pedagogía). Vol. 9. No. 1, (2020): 79-90.

Conole, Gráinne. Review of pedagogical models and their use in e-learning (2010), https://www.slideshare.net/grainne/pedagogical-models-and-theiruse-in-elearning-20100304 (marzo 2020)

Duart, Josep y Lupiáñez, Francisco. "E-strategias en la introducción y uso de las TIC en la universidad". RUSC. Universities and Knowledge Society Journal. Vol. 2. No. 1, (2005): 5-31.

Dussán, Ciro y Guevara, Fabián. "Comparativo entre la tecnología de redes $4 G$ y $5 G$ y los beneficios de su implementación en Colombia". Tesis de la tecnología en Sistemas de Información, Universidad Santiago de Cali, 2019.

Fernández, Natalia. Las prácticas docentes en propuestas de educación en línea. Comunidad de Práctica para la formación e investigación de prácticas de tutoría - de profesionales con y sin formación de base pedagógica - en propuestas de enseñanza en línea. Buenos Aires: PENT, 2013.

García, Francisco. "Estado actual de los sistemas e-learning". Revista Teoría de la Educación. Vol. 2. No. 6, (2005): 1-6.

García, Lorenzo. "Historia de la educación a distancia". RIED: revista iberoamericana de educación a distancia. Vol. 2. No. 1, (1999):11-40.

García, Noe et al., "Facebook como Entorno Virtual de Enseñanza Aprendizaje para diversificar la asignatura de historia en el contexto multigrado". En: Investigaciones sobre problemas educativos y sociedad. México: Universidad Autónoma de Zacatecas, 2018. 671-680.

Góngora, Yisell y Martínez, Olga. "Del diseño instruccional al diseño de aprendizaje con aplicación de las tecnologías". Teoría de la Educación. Educación y Cultura en la Sociedad de la Información. Vol. 13. No. 3, (2012): 342-360.

Gros, Begoña. "La evolución del e-learning: del aula virtual a la red". RIED, Revista Iberoamericana de Educación a Distancia. Vol. 21, No. 2, (2018): $1-15$. 
Guerrero, Claudia. "Diagnóstico de la deserción en dilemas sociales en el aprendizaje colaborativo en ambientes e-learning". Trabajo de Investigación de Maestría en E-learning, Universidad Autónoma de Bucaramanga, 2011.

Harari, Yuval. Homo Deus. Barcelona. Debate, 2016.

Harasim, Linda et al. Redes de aprendizaje. Guía para la enseñanza y el aprendizaje en red. Barcelona: Gedisa, 2000.

Kamarga. Hansiswany. "Constructing online based history learning: comparison of learning content management system (LCMS) to learning management system (LMS). Historia. Vol. 12. No. 2, (2011): 225-273.

Llorente, María. "El tutor en E-learning: aspectos a tener en cuenta". Edutec. Revista Electrónica de Tecnología Educativa. Vol. 20, (2006): 1-16.

Martínez, Alberto. "Formación y experiencia en la universidad". Revista colombiana de Educación. No. 70, (2016): 305-317.

McAnally, Lewis. "La educación en línea, su complejidad y las instituciones de educación”. En Memorias Virtual Educa Brasil 2007. São José dos Campos: Virtual Educa, 2007.

Ministerio de Educación Nacional (MEN). Directiva Ministerial No. 04: Uso de tecnologías en el desarrollo de programas académicos presenciales (22 de marzo de 2020). Bogotá: MEN, 2020, https://www.mineducacion.gov. co/1759/articles-394296_recurso_1.pdf (abril 2020).

OECD Development Centre Studies. E-learning in Higher Education in Latin America. París: OECD Publishing, 2015.

Pérez, Luis. "Tecnología educativa radiofónica en la frontera colombo-venezolana a mediados del siglo XX". Anuario Colombiano de Historia Social y de la Cultura. Vol. 42. No. 1, (2015): 145-176.

Pérez, Luis. "Tendencias y concepciones del E-learning en investigaciones educativas innovadoras". En: Innovación docente e investigación en educación. Madrid: MadridDykinson-Universidad de Murcia, 2020. 451-460.

Pérez, Luis. Revoluciones tecnoeducativas de los europeos civilizadores. Bucaramanga: División de Publicaciones UIS, 2014. 
Pérez. Luis. Historia del Empresarismo en el nororiente de Colombia. Tomo 3. Empresas educativas e innovaciones didácticas en Santander. Bucaramanga: UNAB-Luis Pérez, 2015.

Pérez, María y Guitert, Montse. Aprender y enseñar en línea. Barcelona: FUOC, 2011.

Planella, Jordi et al. Desarrollo organizativo del e-learning. Aspectos sociales y culturales del e-learning. Barcelona: UOC, 2003.

Salinas, Jesús. Innovación educativa y uso de las TIC. Sevilla: Universidad internacional de Andalucía, 2008.

Siemens, George. "Connectivism: A Learning Theory for the Digital Age". International Journal of Instructional Technology and Distance Learning. Itdl, 2005, http://www.itdl.org/Journal/Jan_05/article01.htm (agosto 2019)

Tarasow, Fabio et al. "La educación en línea a través de diversos dispositivos tecno-pedagógicos". En: Memorias del TIES 2012 III Congreso Europeo de Tecnologías de la Información en la Educación y en la Sociedad: Una visión crítica. Barcelona: Esbrina, 2012.

Tennyson, Robert. The impact of the Cognitive Science Movement on Instructional ID Fundamentals. Instructional design fundamentals: a reconsideration. New Jersey: Educational Technology Publications, 1995.

Toffler, Alvin. La tercera ola. Barcelona: Plaza y Janés, 1993.

Torras, Eulália. Aproximación conceptual a la enseñanza y aprendizaje en línea. Barcelona: FUOC, 2015.

Universidad Autónoma de Bucaramanga (UNAB) (2020). Bienvenido a Canvas. Tu experiencia online se transformará. Bucaramanga: UNAB, 2020, https:// canvas.unab.edu.co/ (abril 2020).

Universidad de Salamanca. Los MOOC: Historia, Características, Realidades y Tendencias. Salamanca: Universidad de Salamanca, 2017, http://repositorio. grial. eu/handle/grial/890 (marzo 2010). 


\section{Citar este artículo}

Pérez Pinzón, Luis Rubén. "Orígenes y transformaciones del aprendizaje en línea (E-learning). Innovaciones educativas mediadas por paradigmas tecnológicos". Revista Historia de la Educación Colombiana. Vol. 24 No 24 (2020): 105-132

DOI: https://doi.org/10.22267/rhec. 202424.74 